Goldschmidt 2021 Abstract

https://doi.org/10.7185/gold2021.4054

\section{High mercury sorption in low organic matter aquifer material using column experiments.}

\author{
DAVID S. MCLAGAN ${ }^{1}$, CARINA ESSER ${ }^{1}$, LORENZ \\ SCHWAB $^{2}$, JAN PIETRUCHA ${ }^{1}$, JAN G. WIEDERHOLD ${ }^{2}$, \\ STEPHAN M. KRAEMER ${ }^{2}$ AND HARALD UWE BIESTER ${ }^{1}$ \\ ${ }^{1}$ Technische Universität Braunschweig \\ ${ }^{2}$ University of Vienna
}

Presenting Author: d.mclagan@tu-braunschweig.de

Sorption of mercury $(\mathrm{Hg})$ in soils is suggested to be predominantly associated with organic matter (OM). Previous soil column experiments have demonstrated increased equilibrium sorptive capacity for $\mathrm{Hg}$ with increasing $\mathrm{OM}$ content[1]. We used a series of column experiments to examine $\mathrm{Hg}$ sorption and subsequent desorption in low $\mathrm{OM}(<0.5 \%)$, uncontaminated aquifer material. Highly soluble $\mathrm{HgCl}_{2}$ solutions $\left(46.1 \pm 1.1\right.$ and $\left.144 \pm 6 \mathrm{mg} \cdot \mathrm{L}^{-1}\right)$ were applied to eight syringe columns of $70.1 \pm 0.1 \mathrm{~g}[\mathrm{dw}]$ aquifer material. Two columns were sacrificed for solid phase analyses halfway through sorption, three columns sacrificed at maximum sorption, and three columns after desorption with simulated uncontaminated groundwater. Liquid phase total $\mathrm{Hg}$ concentrations $(\mathrm{THg})$ were measured continuously throughout sorption, equilibrium, and desorption phases. Additionally, liquid and solid phase $\mathrm{Hg}$ speciation/fractionation and stable $\mathrm{Hg}$ isotope analyses were made.

Despite the very low $\mathrm{OM}$ content, $\mathrm{Hg}$ equilibrium sorptive capacity in these columns was very high: $2250 \pm 50$ and $3310 \pm 80 \mathrm{mg} \cdot \mathrm{kg}^{-1}$ for the 46.1 and $144 \mathrm{mg} \cdot \mathrm{L}^{-1}$ solution experiments, respectively. These values are similar to those determined for high OM (9-25\%) Amazonian soils[1]. Sorption fitted a S-shaped uptake profile, although $\mathrm{THg}$ continued to increase very slowly during the "equilibrium phase" (Fig. 1). Desorption with the simulated groundwater fitted an exponential rate of decrease in $\mathrm{THg}$ in the liquid phase. 47.2 \pm 0.7 and $42.7 \pm 1.0 \%$ of the sorbed $\mathrm{Hg}$ was removed during desorption of the 46.1 and $144 \mathrm{mg} \cdot \mathrm{L}^{-1}$ experiments, respectively; yet, some $\mathrm{Hg}$ was still being released at the end of desorption experiments. This suggests the majority of $\mathrm{HgCl}_{2}$ remained unchanged and the highly soluble species was likely physically sorbing to mineral surfaces such as $\mathrm{Fe} / \mathrm{Mn}$-oxides and subsequently re-released by flushing with the uncontaminated solution. This speciation was confirmed by liquid and solid phase speciation/fractionation analyses. Nonetheless, elemental $\mathrm{Hg}\left(\mathrm{Hg}^{0}\right)$ was detected in speciation/fractionation analyses of solid (Fig. 2) and liquid phases. Reduction to $\mathrm{Hg}^{0}$ has been identified in aquifers contaminated by $\mathrm{HgCl}_{2}$ [2]. We endeavour to present $\mathrm{Hg}$ stable isotope data for liquid and solid phase samples at the conference, which may reveal additional information on biogeochemical processes occurring in the aquifer.

[1] Miretzky et al. (2005), Chemosphere, 60, 1583-1589.

[2] Bollen et al. (2008), Water Research, 42, 91-100.

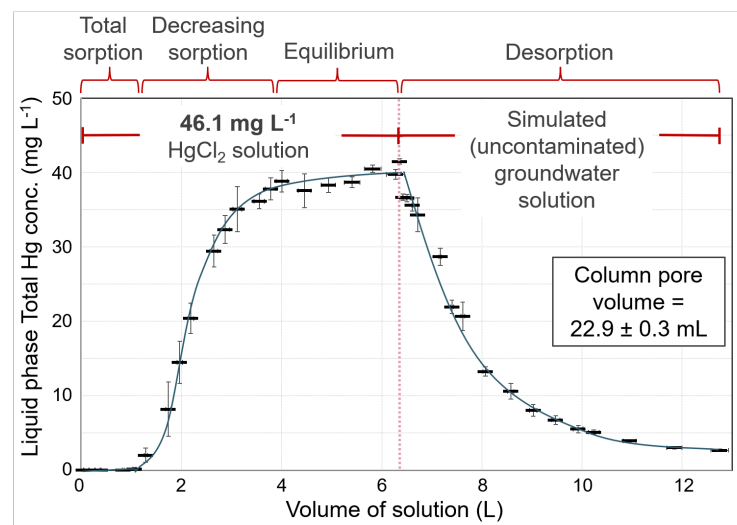

Fig. 1: Liquid phase THg of sorption \& desorption experiment

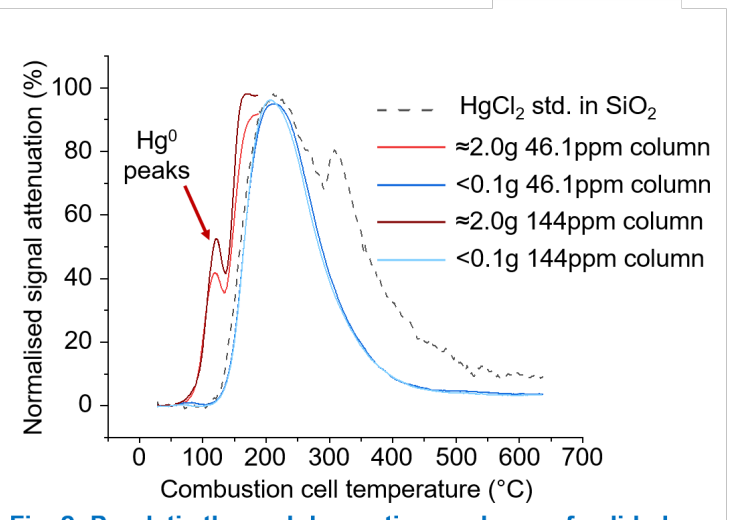

Fig. 2: Pyrolytic thermal desorption analyses of solid phase 